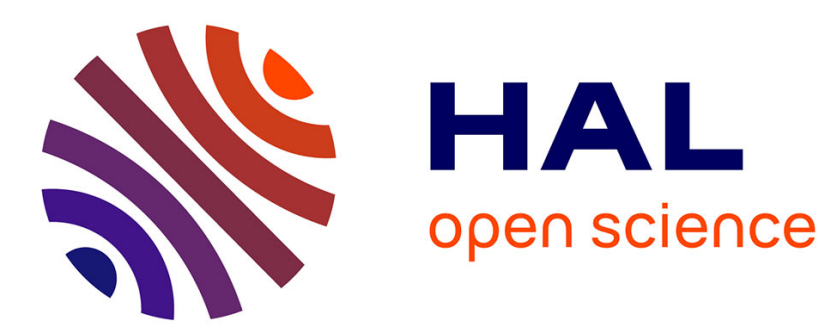

\title{
Structural iron in dioctahedral and trioctahedral smectites: A polarized XAS study
}

\author{
N. Finck, M. L Schlegel, A. Bauer
}

\section{To cite this version:}

N. Finck, M. L Schlegel, A. Bauer. Structural iron in dioctahedral and trioctahedral smectites: A polarized XAS study. Physics and Chemistry of Minerals, 2015, 42 (10), pp.847-859. 10.1007/s00269015-0768-3 . cea-02383813

\section{HAL Id: cea-02383813 https://hal-cea.archives-ouvertes.fr/cea-02383813}

Submitted on 28 Nov 2019

HAL is a multi-disciplinary open access archive for the deposit and dissemination of scientific research documents, whether they are published or not. The documents may come from teaching and research institutions in France or abroad, or from public or private research centers.
L'archive ouverte pluridisciplinaire HAL, est destinée au dépôt et à la diffusion de documents scientifiques de niveau recherche, publiés ou non, émanant des établissements d'enseignement et de recherche français ou étrangers, des laboratoires publics ou privés. 


\title{
Structural iron in dioctahedral and trioctahedral smectites: A polarized XAS study
}

\author{
N. Finck ${ }^{1 *}$, M. L. Schlegel ${ }^{2}$, A. Bauer ${ }^{1}$ \\ ${ }^{1}$ Institute for Nuclear Waste Disposal (INE), Karlsruhe Institute of Technology (KIT), P.O. Box 3640, 76021 \\ Karlsruhe, Germany ( \\ ${ }^{2}$ CEA, DEN/DANS/DPC/SEARS/LISL, Building 391, 91191 Gif-sur-Yvette, France.
}

\begin{abstract}
The chemical form of structural $\mathrm{Fe}$ in smectites influences many physicochemical properties of these clay minerals. Powder EXAFS data for structural Fe in smectites have been reported, however, the preferred orientation of clay platelets with respect to the X-ray beam may lead to erroneous conclusions on the local chemical environment. Dioctahedral montmorillonite and for the first time trioctahedral hectorite were prepared as textured samples and the $\mathrm{Fe}$ local environment was probed by analysis of the X-ray absorption pre-edge peaks at the magic angle and by polarized EXAFS (P-EXAFS) spectroscopy. Compared to powder measurements, overlapping contributions from shells with distinct orientations can be filtered more easily by P-EXAFS, thus decreasing uncertainties on structural parameters.
\end{abstract}

The pre-edge spectrum for montmorillonite is similar to spectra commonly reported for dioctahedral smectites. In contrast, the pre-edge spectrum of hectorite is notably distinct, and hints to either differences in the site symmetry and/or in covalence. In both smectites, $\mathrm{Fe}$ is surrounded by a first $\mathrm{O}$ shell at a distance consistent with sixfold coordinated $\mathrm{Fe}(\mathrm{III})$, suggesting that $\mathrm{Fe}(\mathrm{III})$ is located in the smectite octahedral sheet. This is corroborated by the distances and orientations of neighboring cationic shells, such as in-plane ( $\mathrm{Mg}, \mathrm{Al})$ and outof-plane Si shells. For montmorillonite, the results indicate Fe substitution for $\mathrm{Al} / \mathrm{Mg}$ in the octahedral sheet, and a number of Fe neighbors consistent with random distribution in the octahedral sheet. For hectorite, results indicate a slight tendency for Fe atoms to form pairs in octahedral sheets; however, low numbers of neighboring cations were obtained, presumably a consequence of the presence of vacancies and/or $\mathrm{Li}$ in the vicinity of $\mathrm{Fe}$, or of the coexistence of Fe and $\mathrm{Mg}$ neighbors with mutually cancelling EXAFS waves. Consistent with pre-edge data, the coordination numbers can also indicate some incoherency in Fe-cation interatomic distances in hectorite as a consequence of site distortion. These results suggest that $\mathrm{Fe}^{3+}$ in hectorite locally distorts the structure of the trioctahedral phyllosilicate, and tends to aggregate charge-deficient (i.e. vacant or $\mathrm{Li}^{+}$-containing) octahedral sites.

\section{Keywords}

Montmorillonite, Hectorite, Iron, polarized XAS 


\section{Introduction}

Smectites are widespread clay minerals forming under surface and subsurface conditions (Meunier, 2005) and widely occur in weathering formations and sediments (Güven, 1988). These small, flat minerals possess a large surface area and permanent layer charge. As a consequence, they can absorb and retain a variety of ions or molecules and thus they dominate the physicochemical properties in the systems in which they are present. Their high reactivity has also spurred important industrial applications such as catalysis (e.g., (Swarnakar et al., 1996; Güven, 2009) and health (Williams et al., 2009). Smectites are also constituents of bentonites and confer to these materials cost-efficient mechanical, hydraulic and chemical properties. Bentonites are extensively used as constituents of engineered barriers for the isolation of pollutants, and could be used as backfill in high-level nuclear waste repositories (Gates et al., 2009). Finally smectites such as hectorite can form as secondary minerals during the alteration of nuclear glass containing high-level waste (Thien et al., 2010). These newly formed minerals can further react with hazardous radionuclides released by alteration of nuclear glass. Thus, it is important to understand the smectite crystallochemical properties which ultimately control their reactivity.

Smectites can exhibit a large variation in chemical compositions as a result of their versatile structure and of cationic substitution in crystal sites. For example, montmorillonite, the common aluminum smectite in soils and sediments, is made by the condensation of one octahedral sheet sandwiched between two tetrahedral sheets (Figure 1), forming a TOT structure. Two-third of the octahedral sites are occupied mostly by $\mathrm{Al}$ (III), forming a dioctahedral framework in which $\mathrm{Al}(\mathrm{III})$ can be substituted by cations such as $\mathrm{Mg}$ (II) or $\mathrm{Fe}$ (II,III) (Stucki, 1988). In contrast, in trioctahedral hectorite all octahedral sites are filled, mostly by $\mathrm{Mg}(\mathrm{II})$, which can be substituted by $\mathrm{Li}(\mathrm{I})$ or trace amounts of Fe(II,III). Not only the extent, but also the distribution of chemical substitution can affect the chemical reactivity of smectite (Mering and Glaeser, 1954). For example, reduction or oxidation of redox sensitive cations will modify the layer charge and thus alter properties such as swelling and/or cation exchange capacity (Gates et al., 1996; Gates et al., 1998), which in turn may affect the retention capacities of bentonites.

Structural Fe in clay minerals can significantly impact the redox properties in the environments where they are present. The reduction of Fe(III) in smectite can be achieved by microbial (e.g. Pentráková et al., 2013) and by chemical treatments (e.g. Komadel et al., 2006; Stucki, 2006). For example, ferruginous smectite can be reduced by dithionite within hours and the reduction proceeds from the basal surfaces rather than from the particle edges (Komadel et al., 2006). Fe(II) in clay minerals is able to reduce heavy metals (Bishop et al., 2014) and radionuclides (Bishop et al., 2011; Yang et al., 2012), thereby modifying their mobility and availability. In contrast, $\mathrm{Fe}$ (III) may act as terminal electron acceptor for iron-reducing bacteria, which provides a mechanism of structural Fe(II) (re)generation (Ernstsen et al., 1998). The magnitude and reversibility of these reactions largely depend on the Fe local environment in the octahedral sheet, i.e., the formation of a solid solution or the occurrence of Fe-rich clusters (Drits and Manceau, 2000) which can be controlled in part by the smectite structure. For example, in dioctahedral smectites, two octahedral sites of distinct sizes can be identified, and Fe(III) would preferentially enter the largest one (Tsipursky and Drits, 1984), and thus be relatively dispersed. In contrast, preferential clustering of Fe was observed in trioctahedral micas, i.e., non-swelling phyllosilicates with TOT layers as in smectites (Manceau et al., 1990). This suggests that Fe distribution may differ depending on the 
octahedral sheet framework (dioctahedral or trioctahedral) of smectites. Unfortunately, no study reported unambiguous evidence for random Fe distribution in trioctahedral smectites so far.

X-ray absorption spectroscopy (XAS), and more specifically extended X-ray absorption fine structure (EXAFS) spectroscopy, have proven to be reliable techniques to probe the molecular environment of transition metals. Powder EXAFS spectroscopy was used to investigate the Fe environment in montmorillonite (SWy-1) (Vantelon et al., 2003). No Fe-Fe pair was detected, suggesting that the structure has an ordered Fe distribution obeying an exclusion rule in the octahedral sheet. The spectroscopic analysis of such powder spectra is however complicated by textural effects which are difficult to avoid during sample preparation of minerals having a layered structure (Manceau, 1990b). Powder EXAFS spectra for such anisotropic samples should be recorded with the sample plane oriented at the magic angle (at which any angular dependence is extinguished), otherwise XAS analysis will provide an inaccurate description of the local environment. Unfortunately, information concerning sample preparation and orientation with respect to the in-coming X-ray beam is most of the time missing. Additionally, EXAFS analysis for such samples is complicated by interferences between EXAFS waves scattered by neighboring shells located at similar distances from the absorber. This complication can be overcome by polarized EXAFS (P-EXAFS) spectroscopy which can discriminate the contributions of absorberbackscatterer pairs with distinct crystallographic orientations. This is of high interest in investigations on clay minerals where cationic shells from the tetrahedral and octahedral sheets are separated by $<0.25 \AA$. The theoretical background and principle of P-EXAFS applied to smectite preparation is well documented (e.g. Manceau et al., 1998; Schlegel et al., 1999; Manceau et al., 2000a). Thus P-EXAFS can provide unique information on the nature, number, distance and orientation of neighboring shells. For Fe, this information can be complemented by the analysis of pre-edge peaks which are related to quadrupolar and (forbidden) dipolar transitions from the $1 s$ to $d$ orbitals. The position and amplitude of these peaks is known to be sensitive to the oxidation state and the site symmetry of Fe (Manceau and Gates, 1997; Wilke et al., 2001). The combination of pre-edge peaks and P-EXAFS spectroscopy was powerful in determining the Fe short-range environment in Ferich smectites such as nontronites (Manceau et al., 2000a; Manceau et al., 2000b; Gates et al., 2002).

In this study, the Fe chemical state and distribution in dioctahedral montmorillonite (SWy-1) and trioctahedral hectorite (SHCa-1) were investigated by XAS. These smectites are taken as representative of dioctahedral and trioctahedral clay minerals. In addition, these minerals are also model systems for material present in the backfill of a nuclear waste repository site and as a secondary phase frequently detected in alteration experiments of nuclear glass, respectively. As such, thorough determination of their crystallochemical properties is useful to improve the robustness of long-term models of waste confinement. In this study, oriented self-supporting films were prepared in order to probe the Fe $K$-edge by P-EXAFS spectroscopy for SWy- 1 and, for the first time, SHCa-1. Also, P-XAS data collected and analyzed to understand how Fe can affect the local structural properties of dioctahedral or trioctahedral smectites.

\section{Experimental}

\section{Samples}

Montmorillonite (SWy-1) and hectorite (SHCa-1) were purchased from the Source Clays Repository of the Source Clay Mineral Project (SCMP). Montmorillonite was purified according to a standard procedure 
described in (Golubev et al., 2006) and the fraction $<1 \mu \mathrm{m}$ was isolated. For hectorite the fraction $<2 \mu \mathrm{m}$ was isolated by sedimentation and purified following the procedure described in (Schlegel et al., 1999). The purified montmorillonite and hectorite fractions were saturated with $\mathrm{Na}$. The elemental compositions of the purified fractioned samples were determined by acid digestion and ICP-MS (Thermo X-Series II) analysis of the resulting solutions. The results are presented in Table 1. Besides the elements listed in Table 1, hectorite also contains large amounts of fluorine (2.7 wt\% for the SCMP hectorite, Thomas et al., 1977), but this element was not quantified because the analysis involved acid digestion using concentrated HF.

To remove possible X-ray amorphous ferric oxides during the purification, hectorite underwent a treatment with dithionite-citrate-bicarbonate that imposes strongly reducing conditions, followed by treatment with hydrogen peroxide that imposes strongly oxidizing conditions. With dithionite, a complete reduction of structural Fe from a trivalent to a divalent oxidation state can be achieved in smectites, such as reported for the Fe-rich SWa-1 (Gorski et al., 2012) and for the montmorillonite SWy-2 (Neumann et al., 2011), and subsequent re-oxidation can be achieved with hydrogen peroxide (Gorski et al., 2013). Furthermore, reported spectroscopic data showed that structural changes in the Fe coordination environment and in the silicate lattice can be caused by the Fe reduction and that these are not fully reversible (e.g., SWy-2 and SWa-1, (Neumann et al., 2011; Gorski et al., 2013)). Similarly to the reported montmorillonite data, Fe in hectorite may also have underwent a reduction-oxidation cycle, resulting in partly irreversible structural modifications. However, our infrared spectra do not reveal any strong perturbation of the hectorite lattice, certainly due to the low Fe content.

Purified Na-saturated smectites were first characterized by powder X-ray diffraction and Fouriertransform infrared (FTIR) spectroscopy. The X-ray diffractograms were collected on oriented samples with a D8 Advance (Bruker) diffractometer $\left(\mathrm{Cu} K_{\alpha}\right.$ radiation) equipped with an energy dispersive detector (Sol-X). The FTIR spectra were obtained with a Bruker IFS 55 spectrometer, equipped with an ATR (Attenuated Total Reflectance) cell and an MCT (Mercury Cadmium Telluride) detector. Self-standing films were prepared by slow filtration of the clay suspensions on a $0.025 \mu \mathrm{m}$ pore size filter (Millipore) (Schlegel et al., 1999). This protocol readily provided highly textured self-supporting films to perform polarized XAS experiments, with $a$ and $b$ layer axes of the crystallites randomly oriented in the plane of the film.

\section{X-ray absorption spectroscopy $(X A S)$}

Polarized Fe $K$-edge XAS data of the oriented clay samples were collected at the FAME beamline (Proux et al., 2005) at the ESRF (Grenoble, France) with a ring energy of $6 \mathrm{GeV}$ and a ring current of 50-90 mA. The data were collected in fluorescence-yield detection mode using a 30-element Ge solid state detector (Canberra) at angles $(\alpha)$ between the electric field of the X-ray beam and the clay layer plane of 10, 35, 55 and $80^{\circ}$. The energy calibration was done by setting the first inflection point of the Fe $K$-edge of an iron foil at $7112.0 \mathrm{eV}$.

The pre-edge spectra were modeled by pseudo-Voigt line shapes (Westre et al., 1997) after subtraction of the baseline with an exponential function. The energy position, the full width at half-maximum and the peak height were fit using a fixed 50:50 Gaussian:Lorentzian ratio for the peaks. The pre-peak intensity was calculated as the integrated areas of the pseudo-Voigt functions used for peak modeling. 
Analysis of the EXAFS data was performed following standard procedures by using the Athena and Artemis interfaces to the Ifeffit software (Ravel and Newville, 2005). The spectra were extracted from the raw data and the Fourier transforms (FTs) were obtained from the $k^{3} \times \chi(k)$ functions $\left(3.2-10.2 \AA^{-1}\right.$ for both samples at all angles). The spectral data were fit in $R$ space $(1.3-3.8 \AA$ for both samples at all angles) using phase and amplitude functions calculated with feff8.4 (Ankudinov et al., 1998). The amplitude reduction factor $\left(\mathrm{S}_{0}{ }^{2}\right)$ was set to 0.70 , a value well suited to properly fit the data of $\alpha$-Fe (data not shown). In order to generate theoretical paths, the published structures of montmorillonite (Tsipursky and Drits, 1984) and hectorite (Breu et al., 2003) were used with the absorber $(\mathrm{Fe})$ located at octahedral position. Since the differences in backscattering amplitude between neighboring $\mathrm{Mg}, \mathrm{Al}$ and $\mathrm{Si}$ are limited, the XAS fitting models were simplified. In montmorillonite, octahedral and tetrahedral contributions were fit by using only $\mathrm{Al}$ and $\mathrm{Si}$ backscatterers, respectively. In hectorite, only $\mathrm{Mg}$ (octahedral) and $\mathrm{Si}$ (tetrahedral) contributions were considered. Similarly, $\mathrm{O}$ and F only differ by $\mathrm{Z} \pm 1$ so that $\mathrm{F}$ neighbors in hectorite can be fitted with EXAFS phase and amplitude functions for $\mathrm{O}$ with only minimal discrepancy. Thus the first coordination shell of $\mathrm{Fe}$ in hectorite can be considered to be made of $\mathrm{O}$ atoms only for fitting purposes.

For a given film, the data were fit simultaneously at all angles using a single value of $\Delta E$, and for a given shell a common bond length and mean square displacement ("Debye-Waller" factor). The Fe:Al (montmorillonite) and Fe:Mg (hectorite) ratios were kept equal at all angles. The uncertainties are typically \pm $0.02 \AA$ on the distances for well-resolved atomic shells and $\pm 20 \%$ on the coordination numbers. The experimental uncertainty on $\alpha$ is estimated to $\pm 1^{\circ}$. The fit quality was quantified by the $R_{f}$ factor representing the absolute misfit between theory and data (Ravel, 2000).

\section{Results and discussions}

\section{$X$-ray diffraction and infrared spectroscopy}

X-ray diffractograms for the two smectites are presented in Figure 2. The basal spacing for montmorillonite $(d(001)=12.2(2) \AA)$ and hectorite $(d(001)=14.8(2) \AA)$ are typical of smectite with one or two interlayer water molecules, respectively (Meunier, 2005). Quartz (peak at $26.6^{\circ} 2 \theta$ ) is also present in small quantities in montmorillonite, but could not be detected in hectorite. Quartz does not contain Fe and thus will not affect XAS measurements. No other crystalline phase could be detected and the flat backgrounds of the diffractograms indicate the absence of additional X-ray amorphous phase.

The IR spectrum of montmorillonite (Figure 2) matches reported data (Madejova and Komadel, 2001), with an $-\mathrm{OH}$ stretching band of structural hydroxyl groups at $3623 \mathrm{~cm}^{-1}$ and $\mathrm{Si}-\mathrm{O}$ stretching bands at $989 \mathrm{~cm}^{-1}$ and $1116 \mathrm{~cm}^{-1}$ (longitudinal mode). The spectrum also contains AlAl-OH, AlFe(III)-OH and AlMg-OH deformation bands at $914 \mathrm{~cm}^{-1}, 882 \mathrm{~cm}^{-1}$ and $848 \mathrm{~cm}^{-1}$, respectively. The spectrum of hectorite also matches reported data (Madejova and Komadel, 2001), with $-\mathrm{OH}$ stretching bands of structural hydroxyl groups (3674 $\left.\mathrm{cm}^{-1}\right)$ and bonded water $\left(3621 \mathrm{~cm}^{-1}\right)$. The presence of adsorbed water is further indicated by two broad bands at $3380 \mathrm{~cm}^{-1}$ (-OH stretching) and $\sim 3265 \mathrm{~cm}^{-1}$ (overtone of $-\mathrm{OH}$ deformation of water). This finding indicates that the interlayer of hectorite contains more water than that of montmorillonite for which these bands are absent, what is consistent with 2-layer and 1-layer hydrate state, respectively, determined by XRD. In hectorite, the bands at $960 \mathrm{~cm}^{-1}$ and $689 \mathrm{~cm}^{-1}$ correspond to $\mathrm{Si}-\mathrm{O}$ stretching and the band at $651 \mathrm{~cm}^{-1}$ to $\mathrm{Mg}_{3}-\mathrm{OH}$ deformation. 
The trioctahedral character of this smectite is revealed by the $\mathrm{Mg}_{3}-\mathrm{OH}$ band and the position of the structural hydroxyl group. The Si-O stretching bands at $780 \mathrm{~cm}^{-1}$ and $797 \mathrm{~cm}^{-1}$ can be related to the presence of quartz in both samples (Madejova and Komadel, 2001). The two bands are of similar intensity in hectorite, but not in montmorillonite, possibly because the band at $797 \mathrm{~cm}^{-1}$ in montmorillonite can also contain contribution from the $\mathrm{Fe}(\mathrm{III}) \mathrm{Mg}-\mathrm{OH}$ bending mode (Gates, 2008). No other phases could be detected.

The XRD and IR data indicate that the smectite preparations were free from Fe-containing ancillary phases, attesting to the success of the purification procedures. Also, $-\mathrm{OH}$ bands where the hydroxyl groups are connected to Fe octahedra were detected in the IR spectrum of montmorillonite, but not in hectorite, probably due to the low $\mathrm{Fe}$ content of this mineral. FeFe- $\mathrm{OH}$ deformation bands were absent in the two spectra, excluding Fe clustering and thus hinting at a random Fe distribution, at least in montmorillonite.

\section{Pre-edge spectroscopy}

The Fe $K$-edge XAS spectra have a weak pre-edge feature $\sim 15 \mathrm{eV}$ below the main absorption edge arising predominantly from $1 s \rightarrow 3 d$ (quadrupolar) transitions. The $1 s \rightarrow 3 d$ transition is electric dipoleforbidden by parity considerations in a centrosymmetric octahedral environment (e.g., $O_{h}$ symmetry) (Westre et al., 1997). However, a very weak pre-edge feature, split into $t_{2 g}$ - and $e_{g}$-like components, is still experimentally observed, the intensity depending on the local symmetry and on the cation electronic properties. The pre-peak intensity can thus be used to evaluate the Fe oxidation state and coordination geometry (Manceau and Gates, 1997; Manceau et al., 2000a; Wilke et al., 2001). For example, a higher pre-edge amplitude is observed for fourfold coordinated Fe compared to sixfold coordinated $\mathrm{Fe}$, a consequence of mixing $3 d$ and $4 p$ atomic orbitals in $T_{d}$ symmetry (Westre et al., 1997).

The pre-edge is located at around $7114.5 \mathrm{eV}$ for both montmorillonite and hectorite (Figure 3), indicating the $\mathrm{Fe}$ is in an oxidation state of $+\mathrm{III}$ in both clays. The intensity of the pre-edges is weak $(\sim 1.5 \%$ of the main edge), suggesting that Fe atoms are predominantly sixfold coordinated. The pre-edge features were modeled with pseudo-Voigt line shapes (Westre et al., 1997) to gain additional information on their amplitude and position (Figure 4). At $\alpha=35^{\circ}$ (polarized and powder XAS data are identical at this angle), the difference in energy (Table 2) of the components for montmorillonite $(1.49 \mathrm{eV})$ compared to hectorite $(1.45 \mathrm{eV})$ is below the uncertainty associated to the position of the features $(\sim 0.1 \mathrm{eV})$. The total pre-peak intensities (i.e., total integrated areas, Table 2) equal 0.097 and 0.094 for montmorillonite and hectorite, respectively. These low values compare with those obtained for sixfold coordinated Fe(III) (Wilke et al., 2001). Also, the total pre-peak intensities are similar in both smectites. Interestingly, the ratio between the intensity of the contributions at lower to higher energies equals 1.31 for montmorillonite and 1.00 for hectorite. The intensity ratio of montmorillonite is close to expectation for octahedral high-spin ferric Fe (3:2) (Westre et al., 1997). The lower value for hectorite may best be explained by site distortion for Fe substituting for $\mathrm{Mg} / \mathrm{Li}$ in the trioctahedral smectite. However, the low pre-peak intensity compared to the main edge suggested that the site is centrosymmetric and that such site distortion is actually limited. Alternatively, the observed difference may be explained by distinct covalence of the chemical bonds between Fe and the surrounding ligands (Westre et al., 1997). The $\mathrm{e}_{\mathrm{g}}$ set of the $3 d$ orbitals is more covalent than the $\mathrm{t}_{2 \mathrm{~g}}$ set due to $\sigma$ bonding with the ligands. Hectorite contains significant amount of fluorine substituting for $\mathrm{OH}$ groups, and because $\mathrm{F}$ has an electronegativity higher than $\mathrm{O}$, the observed 
differences may also be attributed to Fe binding to F in hectorite. Regardless of the correct interpretation, these dissimilarities in pre-peak intensities indicate slight differences in Fe local environments.

The pre-peak intensity ratios do not exhibit a monotonic trend with $\alpha$, consistent with previous observations on Fe-rich phyllosilicate $\left\{\right.$ Dyar, 2001 \#74\}. For montmorillonite, the ratio increases from $10^{\circ}$ to $55^{\circ}$ and then decreases whereas for hectorite it increases from $10^{\circ}$ to $35^{\circ}$ and then decreases. Since a dipole transition would be dichroic in nature, this complex angular behavior suggests that the transition is predominantly quadrupole (Hahn et al., 1982). The weakness of the dipole contribution corroborates the predominantly octahedral nature of the coordination polyhedra \{Munoz, $2013 \# 75$ \}.

\section{EXAFS spectroscopy}

EXAFS spectra. Both sets of P-EXAFS spectra exhibit a significant angular dependence over the whole $k$ range and well-defined isosbestic points are observed, attesting to the high degree of particle orientations in the self-supporting films (Figure 5). The variation in amplitude and position of the maxima at $\sim 4.2,5.3,6.5,8.0$ and $9.1 \AA^{-1}$ are consistent with the presence of atomic shells with distinct orientations, e.g., in-plane $\mathrm{Mg} / \mathrm{Al} / \mathrm{Fe}$ and out-of-plane Si atoms. The large dependence on polarization is also consistent with the successful preparation of highly oriented clay films.

The powder EXAFS spectra recorded at $\alpha=35^{\circ}$ for montmorillonite and hectorite show subtle differences in the position and amplitude of oscillation maxima, e.g., at $k \sim 5.0,6.3$ and $8.0 \AA^{-1}$ (Figure 3). The presence of distinct frequencies suggests that Fe has distinct molecular environments in terms of nature and number of backscattering atoms, consistent with the dioctahedral nature of montmorillonite and the trioctahedral nature of hectorite. This is also clearly seen on the corresponding Fourier transforms (FT) where the contributions from the cationic shells differ.

Fourier transforms. The FTs contain several peaks (Figure 5). Peak A $(R+\Delta R \sim 1.6 \AA)$ corresponds to the first oxygen shell $(\mathrm{O} 1)$ and its magnitude is higher in montmorillonite than in hectorite. Best fits (Figures 6 and 7) were obtained for Fe-O1 interatomic distances of $R_{\mathrm{Fe}-\mathrm{O} 1}=2.01(1) \AA$ in montmorillonite and 2.00(1) $\AA$ in hectorite (Tables 3 and 4). These bond lengths are characteristic of sixfold-coordinated Fe(III) and match reported values for Fe located at clay octahedral sites (Manceau et al., 1998; Manceau et al., 2000a; Vantelon et al., 2003). The greater amplitude of peak A for montmorillonite correlates with a greater number of detected $\mathrm{O} 1$ neighbors, e.g., at $\alpha=35^{\circ}, N_{\mathrm{O} 1}=5.8(5)$ for montmorillonite and 5.1(5) for hectorite (Tables 3 and 4). The slightly lower $N_{\mathrm{O} 1}$ in hectorite can be related to a larger structural disorder resulting in a broader distribution of $\mathrm{Fe}-(\mathrm{O}, \mathrm{F})$ bond lengths (Manceau et al., 2000a) around a mean value, which is consistent with the pre-edge results.

The amplitude of peak A decreases for both smectites, and the decrease is more pronounced in montmorillonite than in hectorite (Figure 5). Fits (Figures 6 and 7) indicate that $N_{\mathrm{O} 1}$ decreases from 6.3(5) at $\alpha=$ $10^{\circ}$ to $4.9(4)$ at $\alpha=80^{\circ}$ for montmorillonite and from 5.4(5) to 4.6(4) for hectorite (Tables 3 and 4). Using the relationship between $N$ as a function of $\alpha$ and the angle $\beta$ between the X-ray absorber-backscatterer pair and the normal to the film plane (Schlegel et al., 1999), the orientation of the O1 shell can be estimated. The calculated values of $\beta_{O I}$ equal $58.1(1.5)^{\circ}$ and $56.9(7)^{\circ}$ for montmorillonite and hectorite, respectively. Though the value 
obtained for montmorillonite deviates significantly from the value expected for fully symmetric octahedra $\left(54.7^{\circ}\right.$ ), they are consistent with the octahedral flattening observed in most hydrous TOT phyllosilicates (Güven, 1988).

Peak B $(R+\Delta R \sim 2.75 \AA)$ corresponds to the sum of contributions from the nearest octahedral ( $\mathrm{Mg}, \mathrm{Al}, \mathrm{Fe})$ shell (montmorillonite) or $(\mathrm{Mg}, \mathrm{Li})$ shell (hectorite), the nearest tetrahedral $\mathrm{Si}$ shell and the nextnearest $\mathrm{O}$ shell. The position, amplitude and angular dependences of this peak depend on the interferences between the EXAFS contributions from the octahedral and tetrahedral sheets. For example, peak B for montmorillonite displays a complex polarization dependence: its amplitude decreases from $\alpha=10^{\circ}$ to $\alpha=35^{\circ}$ and then increases with $\alpha$, and the position and imaginary parts shift to higher $R+\Delta R$ values with $\alpha$ (Figure 5). In smectites, this angular behavior is diagnostic of in-plane predominant contributions from $(\mathrm{Mg}, \mathrm{Al})$ cations in the octahedral sheet, and out-of-plane contributions from tetrahedral Si (Schlegel et al., 1999). This peak was fit assuming $\mathrm{Fe}, \mathrm{Al}$ and $\mathrm{Si}$ contributions at $R_{\mathrm{Fe}-\mathrm{Fel}}=3.02(1) \AA, R_{\mathrm{Fe}-\mathrm{All}}=3.04(1) \AA$ and $R_{\mathrm{Fe}-\mathrm{Si} 1}=3.22(1) \AA$, respectively (Table 3). Best-fit bond distances match values obtained from diffraction data (Tsipursky and Drits, 1984). For increasing $\alpha$ values, the coordination numbers decrease from 0.5(1) to 0.1(1) for the Fe shell, from 3.4(3) to 0.6(1) for the $\mathrm{Al}$ shell, and increase from 1.4(7) to 6.6(7) for the Si shell (Table 3). These angular dependences are consistent with $\mathrm{Al}$ and $\mathrm{Fe}$ shells oriented predominantly in the in-plane dimension while the $\mathrm{Si}$ shell is oriented in the out-of-plane direction. The values number of neighboring atoms obtained at $\alpha=35^{\circ}\left(N_{\mathrm{Fe} 1}\right.$ $=0.4(1), N_{\mathrm{All}}=2.6(3)$ and $\left.N_{\mathrm{Si} 1}=3.4(3)\right)$ are in reasonable agreement with coordination numbers for montmorillonite $(3(\mathrm{Al}, \mathrm{Fe})$ neighbors in-plane and $4(\mathrm{Si}, \mathrm{Al})$ neighbors out-of-plane). The fit results indicate a small but significant contribution from neighboring Fe and thus the presence of Fe-Fe pairs. This finding is based on the ability of P-EXAFS to filter out overlapping contributions from shells with distinct orientations, thereby decreasing uncertainties on structural parameters. This can explain, at least partly, why our results slightly differ from earlier conclusions based on the analysis of powder EXAFS spectra (Vantelon et al., 2003).

In contrast to montmorillonite, the amplitude of peak B in hectorite increases with $\alpha$ and its position varies only slightly (Figure 5). Peak B was modelled considering Mg, Fe and Si shells at $R_{\mathrm{Fe}-\mathrm{Mg} 1}=3.03(1) \AA, R_{\mathrm{Fe}-}$ Fe1 $=3.03(3) \AA$ and $R_{\mathrm{Fe}-\mathrm{Si}}=3.24(1) \AA$, respectively (Table 4). The bond distances are consistent with values obtained from diffraction data for $\mathrm{Mg}$ and $\mathrm{Si}$ shells (Breu et al., 2003) and $R_{\mathrm{Fe}-\mathrm{Fel}}$ is typical of edge-sharing $\mathrm{Fe}$ octahedra. The coordination numbers of octahedral $\mathrm{Mg}$ and Fe decrease from 2.8(2) to 0.6(1) and from 0.3(1) to 0.1(1), respectively, and increase for Si from 2.1(2) to 6.9(7), for increasing $\alpha$ values (Table 4). The angular dependences are consistent with $\mathrm{Mg}$ and Fe shells located in-plane and Si located out-of-plane, but the in-plane number of neighboring $\mathrm{Mg}+\mathrm{Fe}$ are much lower than expected from the smectite composition. For a trioctahedral structure, six octahedral and four tetrahedral cationic neighbors would be expected. The detected number of tetrahedral neighbors equals 3.4(6), reasonably close to the theoretical value of four, but the number of octahedral neighbors equals $\sim 2$, much lower than the expected value of six (Table 4). Several explanations could possibly explain the deviation from the ideal values. First, hectorite contains Li substituting for $\mathrm{Mg}$ (Table 1) and $\mathrm{Li}$ is too light to be detected by EXAFS spectroscopy. The impact of this substitution on $N_{\mathrm{Mg}}$ can be estimated from the $\mathrm{Li}: \mathrm{Mg}$ ratio of $\sim 1: 10$ in hectorite. Assuming random distributions of $\mathrm{Mg}$ and $\mathrm{Li}$ in the octahedral sheet, the detected number of $\mathrm{Mg}$ neighbors should be close to 5.4, a value still significantly higher than the experimental value. Second, as $\mathrm{Fe}(\mathrm{III})$ substitutes for $\mathrm{Mg}$ (II), the increase in local charge may be balanced by vacancies or, more likely by $\mathrm{Li}(\mathrm{I})$ preferential insertion in adjacent octahedral sites, thereby lowering the number 
of detected octahedral neighbors. A third hypothesis is that electronic waves backscattered by octahedral Fe and $\mathrm{Mg} / \mathrm{Al}$ are out of phase (Manceau, 1990a) leading to destructive interferences as can be seen in Figures 6 and 7. Owing to this interference, the apparent numbers of $\mathrm{Fe}$ and $\mathrm{Mg}$ neighbors are mutually lowered and so actual number of neighboring $\mathrm{Fe}$ (and $\mathrm{Mg}$ ) cations. Please note that such interference would also occur in powder spectra, and would be further compounded by the EXAFS contribution of out-of-plane Si. Peak B for hectorite also contains contribution from the next nearest oxygen shell $\left(N_{\mathrm{O} 2}=0.6(1.1)\right)$ located on the basal plane $\left(R_{\mathrm{Fe}-\mathrm{O} 2}=\right.$ 3.48(1) A). This shell is not detected in the dioctahedral smectite because of corrugation of the basal oxygen planes that increases the average spread of the Fe-O2 distances (Manceau et al., 2000b). From the increase of $N_{\mathrm{O} 2}$ with $\alpha$ (Table 4) this shell is clearly located out-of-plane, matching expectation for a shell located at the basal plane.

Two additional $\mathrm{O}$ shells were also used to improve the fit of peak B at higher distances in both smectites (Tables 3 and 4). The $\mathrm{O} 3$ shell originates from $\mathrm{O}$ atoms of adjacent octahedra $\left(R_{\mathrm{Fe}-\mathrm{O} 3}=3.78-3.79 \AA\right)$ and the $\mathrm{O} 4$ shell from atoms of the basal planes of the silicate sheet $\left(R_{\mathrm{Fe}-\mathrm{O} 4}=4.01(1) \AA\right)$, and the bond distances are close to reported values (Tsipursky and Drits, 1984; Breu et al., 2003). For montmorillonite, the number of detected backscatterers at $\alpha=35^{\circ}\left(N_{\mathrm{O} 3}=5.8(1.3)\right.$ and $\left.N_{\mathrm{O} 4}=4.2(1.9)\right)$ match coordination numbers expected for smectites $\left(N_{\mathrm{O} 3}=6\right.$ and $\left.N_{\mathrm{O} 4}=4\right)$, whereas they are much lower than expected for hectorite $\left(N_{\mathrm{O} 3}=2.8(1.5)\right.$ and $N_{\mathrm{O} 4}=$ 1.0(1.3)). This again suggests that the phyllosilicate local structure around Fe(III) is distorted in hectorite.

For montmorillonite and hectorite, $N_{\mathrm{O} 4}$ increases from 2.4(2.4) to 8.0(1.3) and from 0.1(1) to 5.5(5), respectively, for $\alpha$ increasing from $10^{\circ}$ to $80^{\circ}$. These variations match expectations for the $\mathrm{O} 4$ shell located at the smectite basal planes, i.e., in out-of-plane direction. The $\mathrm{O} 3$ coordination number is invariant within uncertainty both for montmorillonite $\left(\mathrm{N}_{\mathrm{O} 3}=5.4(1.6)\right.$ to $6.1(9)$ for $\alpha=10$ to $80^{\circ}$, respectively) and hectorite $\left(\mathrm{N}_{\mathrm{O} 3}=2.4(1.3)\right.$ to 4.1(1.9) for $\alpha=10$ to $80^{\circ}$, respectively). Thus no clear angular dependence can be obtained from these values but they are compatible with the known orientation of the $\mathrm{O} 3$ shell inclined toward the octahedral sheet\{Schlegel, $2001 \# 76$ \}.

\section{Discussion}

X-ray diffraction and infrared data showed that both purified smectites are free from Fe-containing impurities, implying that Fe can only be located in the smectite structure. Infrared data are also consistent with a dioctahedral structure for montmorillonite and a trioctahedral structure for hectorite. The pre-edge and EXAFS spectroscopic data indicate that $\mathrm{Fe}$ is in trivalent oxidation state and located in the octahedral sheet but that the Fe local environments in the two clays are dissimilar. The bond lengths and the angular dependences of the neighboring atomic shells confirm this structural assignment and indicate that the amount of Fe in the tetrahedral sheet is marginal.

In montmorillonite, the number of cationic neighbors detected in-plane $\left(N_{\mathrm{Fe} 1}+N_{\mathrm{All}}=3\right)$ is in agreement with a dioctahedral structure $(N=3)$. Fits to the data are consistent with $\mathrm{Fe}$ substituting for $\mathrm{Al} / \mathrm{Mg}$ in the octahedral layer. Fe-Fe pairs were detected, but with a low number of backscatterers $\left(N_{\mathrm{Fe} 1}=0.4(1)\right)$. The elemental composition (Table 1) indicates a moderate Fe content (2.3 wt $\%)$ and the corresponding $(\mathrm{Al}+\mathrm{Mg}): \mathrm{Fe}$ molar ratio equals 9.4. Considering a fully random $\mathrm{Fe}$ distribution with all Al located in the octahedral sheet, about 0.3 neighboring $\mathrm{Fe}$ atom would be expected. This calculated value is similar to the fit results within 
uncertainties. This finding excludes $\mathrm{Fe}$ clustering and suggests that $\mathrm{Fe}$ is randomly distributed in montmorillonite. Earlier powder EXAFS analysis (Vantelon et al., 2003) also indicated an ordered Fe distribution in this montmorillonite but obeying an exclusion rule. However, powder XAS applied to sheet silicates is affected by larger uncertainties due to the interferences between waves backscattered by shells located at similar distances \{Manceau, 1990 \#55\}. This limitation was overcome in the present study by using the improved sensitivity of PEXAFS spectroscopy, and low number of Fe backscatterers could be unambiguously detected. This improved sensitivity of P-EXAFS spectroscopy was subsequently applied to investigate in detail and for the first time, the Fe distribution in the trioctahedral hectorite.

In hectorite all octahedral sites are filled by various cations such as $\mathrm{Li}, \mathrm{Mg}, \mathrm{Al}$ and $\mathrm{Fe}$, and in addition some $\mathrm{F}$ substitutes for $\mathrm{OH}$ groups. This complex chemical composition of the octahedral sheet could somewhat complicate the powder EXAFS investigation of the Fe environment, thus requiring the use of P-EXAFS spectroscopy. The pre-edge is particularly sensitive to the electronic and geometric structure of the Fe site. The analysis of the hectorite pre-edge suggests differences in the binding environment compared to montmorillonite that may be attributed to some $\mathrm{F}$ substitution for $\mathrm{OH}$ groups. This substitution possibly distorted the site geometry and/or modified the ligand field. Although $\mathrm{OH}$ and $\mathrm{F}$ have similar ionic radii $(r(\mathrm{OH})=1.32 \AA, r(\mathrm{~F})=$ $1.28 \AA$ in II-coordination; Shannon, 1976), F is more electronegative than O, which can decrease the length of the $\mathrm{Fe}-\mathrm{F}$ bond compared to the $\mathrm{Fe}-\mathrm{O}$ one. This is confirmed by reported $R_{\mathrm{Mg}-\mathrm{O}}$ and $R_{\mathrm{Mg}-\mathrm{F}}$ distances in hectorite (Breu et al., 2003) differing by $\sim 0.06 \AA$. The $\mathrm{Fe}-(\mathrm{O}, \mathrm{F})_{6}$ coordination octahedron is thus probably slightly distorted, as corroborated by the slightly larger mean square displacement of the $\mathrm{O} 1$ shell in hectorite $\left(\sigma^{2}=0.006\right.$ $\left.\AA^{2}\right)$ compared to montmorillonite $\left(\sigma^{2}=0.005 \AA^{2}\right)$. The distribution of interatomic distances around a mean value dampens the EXAFS oscillatory contribution from the $(\mathrm{O}, \mathrm{F})_{1}$ shell, thus leading to a slightly lower number of neighboring $(\mathrm{O}, \mathrm{F})$ atoms. Furthermore, the mean square displacement is also larger for octahedral neighbors in hectorite ( $\mathrm{Mg}, \mathrm{Fe}$ ) compared to montmorillonite ( $\mathrm{Al}, \mathrm{Fe}$ ). However, previous NMR data have demonstrated $\mathrm{Fe}-\mathrm{F}$ avoidance in phyllosilicate, i.e., $\mathrm{F}$ is usually not associated to Fe octahedra $\{$ Sanz, 1983 \#79\}. Also, NMR investigation on hectorite failed to report evidence for $\mathrm{Fe}-\mathrm{F}$ association, although this could be due to the minute amount of structural $\mathrm{Fe}(0.2 \% \mathrm{wt})$ compared to the high $\mathrm{F}$ content (up to $5.18 \mathrm{wt} \%$ in some preparations) \{Thomas, $1977 \# 4008$ \}. In addition, any distortion due to the presence of $\mathrm{F}$ is unlikely to result in a large incoherency of the distances between $\mathrm{Fe}$ and the neighboring cations. Indeed, the limited nature of this disorder is attested by the ability of conventional diffraction methods to derive a structural model for hectorite without the need of complex corrections \{Oberlin, $1966 \# 77$;Breu, $2003 \# 7$ \}. The benign nature of this distortion is corroborated by the detection of similar numbers of $\mathrm{Si}$ atoms at very similar distances and comparable mean square displacement in both smectites.

Hectorite has a low $\mathrm{Fe}$ content $(0.2 \mathrm{wt} \%)$ and the corresponding $(\mathrm{Al}+\mathrm{Mg})$ : $\mathrm{Fe}$ molar ratio equals 130 . Considering a fully random distribution of $\mathrm{Fe}$ in the octahedral sheet, the number of neighboring Fe detected by EXAFS would be about 0.06 , slightly smaller than the detected value of $0.2(1)$, values close to the lower limit of detection of EXAFS. This would suggest that Fe atoms within the octahedral sheet may preferentially form some pairs, as reported for trioctahedral micas (Manceau et al., 1990). However, the extended formation of Fe(III) clusters within the octahedral sheet is ruled out because it would have led to much greater $N_{\mathrm{Fe}}$ values. 
$\mathrm{Fe}$ is also surrounded by $\mathrm{Mg}$ neighbors, but the number of detected $\mathrm{Mg}$ is much smaller than the theoretical number for random distribution in hectorite $\left(N_{\mathrm{Mg}}=5.4\right)$, which cannot be explained by structural disorder alone. In hectorite, almost all octahedral sites are filled with cations of similar sizes when sixfold coordinated by oxygen atoms $\left(r^{\mathrm{VI}}(\mathrm{Mg}(\mathrm{II}))=0.72 \AA\right.$ and $r^{\mathrm{VI}}(\operatorname{Li}(\mathrm{I}))=0.76 \AA$ (Shannon, 1976)), but of different charge. The sixfold coordinated $\mathrm{Fe}(\mathrm{III})$ is slightly smaller $\left(r^{\mathrm{VI}}(\mathrm{Fe}(\mathrm{III})=0.65 \AA)\right.$ than $\mathrm{Mg}$ or Li so that the substitution would not result in significant lattice strain. However, Fe(III) insertion in octahedral sites may be locally charge-balanced by octahedral vacancies and/or by Li(I) filling neighboring octahedra. Because Li cannot be detected by EXAFS spectroscopy, these two hypotheses cannot be discriminated, but both of them would result in a low number of detected octahedral neighbors. In fact, the presence of vacancies surrounding $\mathrm{Fe}(\mathrm{III})$ would correspond to the local formation of a dioctahedral-like environment around $\mathrm{Fe}(\mathrm{III})$, a little similar to the $\mathrm{Fe}(\mathrm{III})$ local environment in montmorillonite. However, it would probably lead to a large deficit of local charge. Interestingly, in dioctahedral smectites, deficit of local charge can be decreased by thermal diffusion of $\operatorname{Li}(\mathrm{I})$ cations in vacant octahedra $\{$ Komadel, $2005 \# 80\}$. In the case of hectorite, such a diffusion would not be driven by heat, though, but would readily occur during crystallization. Other charge-balance mechanisms include the deprotonation of hydroxyl groups of the octahedral sheet close to Fe(III), but this would probably lead to severe distortion of the Fe coordination sphere. Still another mechanism of local charge compensation would be the substitution of $\mathrm{Si}(\mathrm{IV})$ by $\mathrm{Al}(\mathrm{III})$ in the tetrahedral sheet. From our EXAFS results, however, we surmise that local charge compensation by $\mathrm{Li}$.

\section{Conclusions}

The local chemical environment around $\mathrm{Fe}$ in the dioctahedral smectite montmorillonite and, for the first time, in the trioctahedral smectite hectorite, was characterized by P-EXAFS spectroscopy. Iron(III) in these smectites is surrounded by in-plane $(\mathrm{Mg}, \mathrm{Al}, \mathrm{Fe})$ atoms and out-of-plane $\mathrm{Si}$ atoms at distances in agreement with previous studies. Furthermore, $\mathrm{Fe}-\mathrm{Fe}$ pairs in limited number could be unambiguously detected, owing to the ability of P-EXAFS to filter out overlapping contributions from shells with distinct orientations. Low numbers of neighboring Fe were detected, and no extended clustering could be observed in either of the minerals, indicating a next-to-random distribution of $\mathrm{Fe}$ in the octahedral sheet. Furthermore, the XAS data indicate that the substitution of $\mathrm{Fe}$ for $\mathrm{Al}$ in the dioctahedral montmorillonite does only marginally affect the local site symmetry. In contrast, the substitution of $\mathrm{Mg}$ (II) by $\mathrm{Fe}(\mathrm{III})$ creates an excess of charge, which is balanced by a deficit of charge in the neighboring octahedra, either in the form of vacancies or as $\operatorname{Mg}$ (II) substitutions by $\operatorname{Li}(\mathrm{I})$. If confirmed, this result would provide a nice example on how impurities in clay minerals can drive heterogeneities in the charge distributions at clay mineral surfaces. The additional amount of lattice flexibility offered by the presence of vacant sites would also explain the ability of hectorite to incorporate large cations such as lanthanides \{Finck, $2009 \# 81$ \}, and, possibly, actinides.

\section{Acknowledgements}

The European Synchrotron Radiation Facility is acknowledged for provision of synchrotron radiation beamtime. We thank O. Proux for assistance during XAS data collection at the FAME beamline. 
Figure 1. Top: Structure of smectite. T: tetrahedral sheet, O: octahedral sheet. Middle: projection down $c^{*}$ of trioctahedral framework. Bottom: projection down $c^{*}$ of dioctahedral framework. Blue triangles are $(\mathrm{Si}, \mathrm{Al}) \mathrm{O}_{4}$ tetrahedra, one tetrahedral sheet is not shown. M1 denotes trans sites, and $\mathrm{M} 2$ cis sites. Figure 2. X-ray diffractogram (basal spacing or $d(001)$ is indexed) and ATR-FTIR spectrum of the clay fractions investigated in this study. Top: Montmorillonite. Bottom: Hectorite.

Figure 3. Comparison of experimental Fe $K$-edge XANES (left), and EXAFS spectra (middle) recorded at $\alpha=35^{\circ}$ for montmorillonite and hectorite with the corresponding Fourier transforms (right).

Figure 4. Normalized pre-edge spectra (solid black line) and best fits (dashed red lines) with individual components (blue and green thin lines) for montmorillonite (left) and hectorite (right).

Figure 5. Experimental P-EXAFS spectra (left) with the corresponding Fourier transforms (right) for montmorillonite and hectorite.

Figure 6. Experimental (solid black lines) and modeled (dashed red lines) polarized Fourier transforms for the montmorillonite data. The right panel indicates the contributions at $\alpha=35^{\circ}$ of the single atomic shells.

Figure 7. Experimental (solid black lines) and modeled (dashed red lines) polarized Fourier transforms for the hectorite data. The right panel indicates the contributions at $\alpha=35^{\circ}$ of the single atomic shells. 
Table captions

Table 1. Main cations content of montmorillonite (SWy-1) and hectorite (SHCa-1) determined by chemical analysis (Other includes oxygen).

Table 2. Results from the pre-edge fitting (uncertainties on the energies are estimated to $0.1 \mathrm{eV}$ and 10 $\%$ on the intensities).

Table 3. Quantitative EXAFS analysis for montmorillonite ${ }^{a}$

Table 4. Quantitative EXAFS analysis for hectorite ${ }^{a}$ 


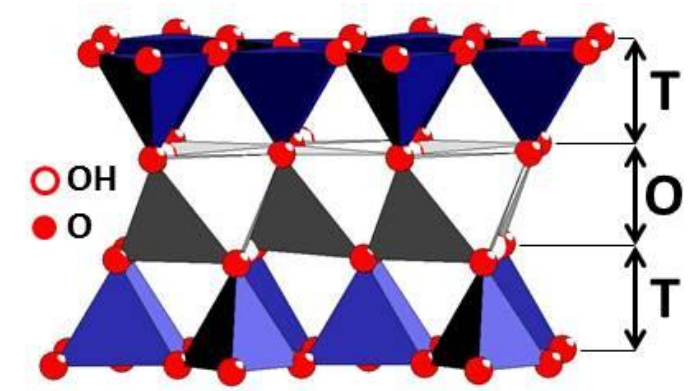

Trioctahedral structure

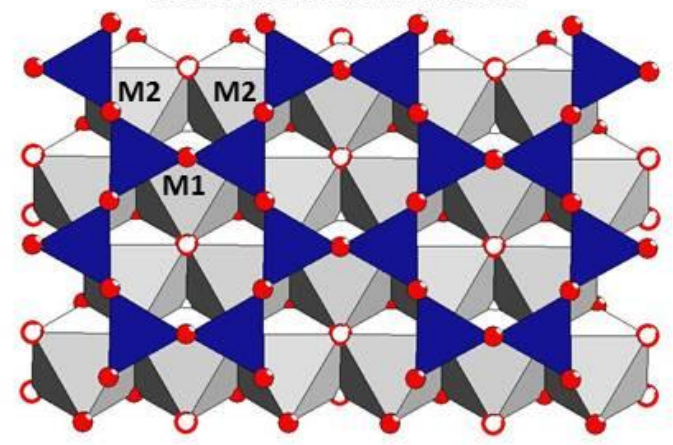

Dioctahedral structure

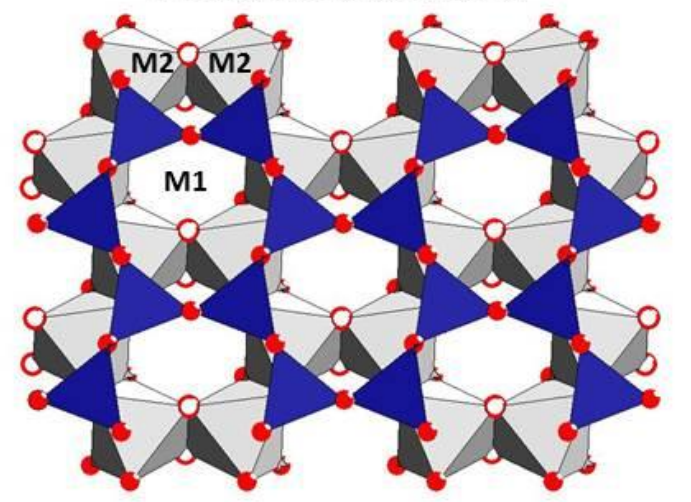

Figure 1. Top: Structure of smectite. T: tetrahedral sheet, O: octahedral sheet. Middle: projection down $c^{*}$ of trioctahedral framework. Bottom: projection down $c^{*}$ of dioctahedral framework. Blue triangles are $(\mathrm{Si}, \mathrm{Al}) \mathrm{O}_{4}$ tetrahedra, one tetrahedral sheet is not shown. M1 denotes trans sites, and M2 cis sites. 

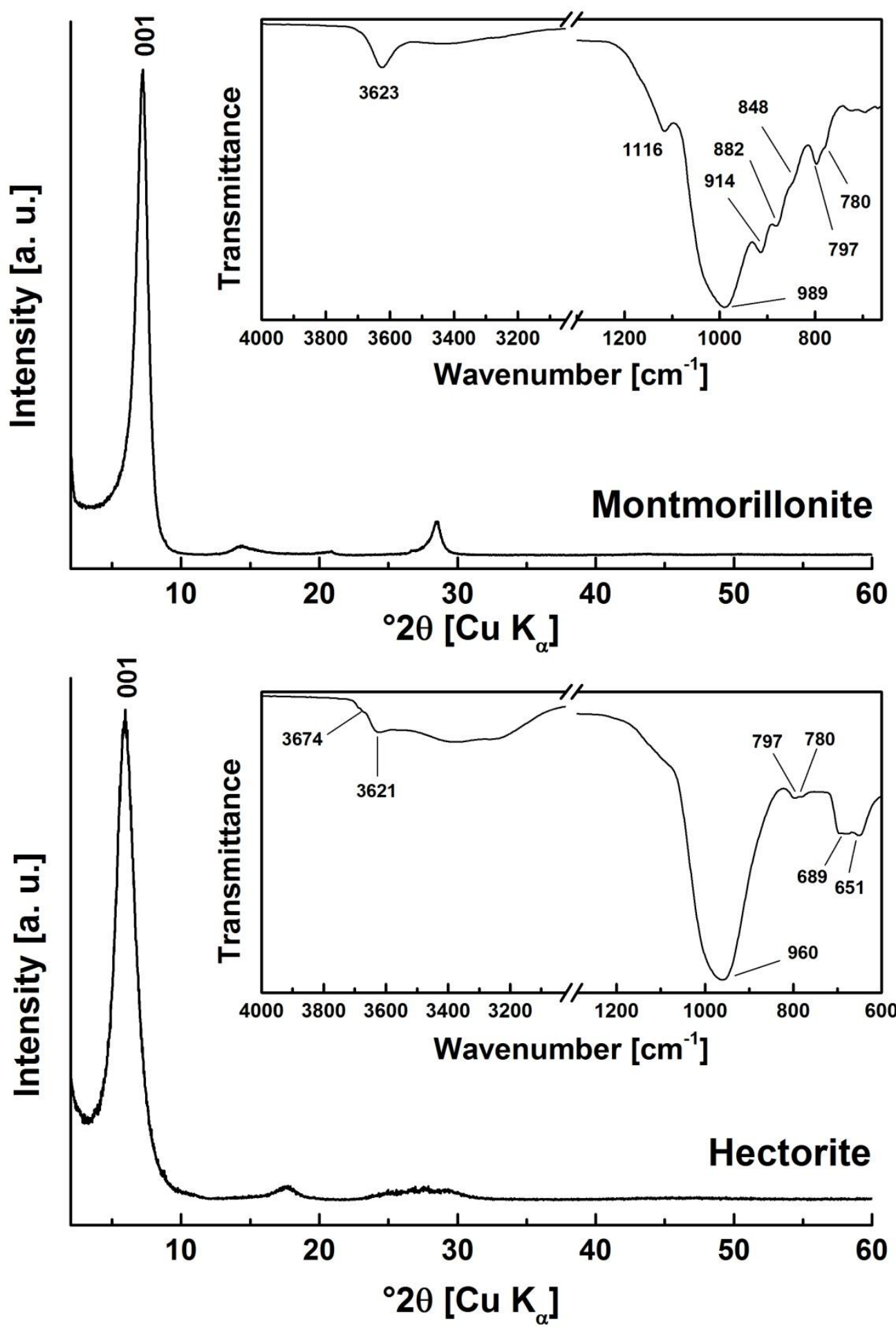

Figure 2. X-ray diffractogram (basal spacing or $d(001)$ is indexed) and ATR-FTIR spectrum of the clay fractions investigated in this study. Top: Montmorillonite. Bottom: Hectorite. 

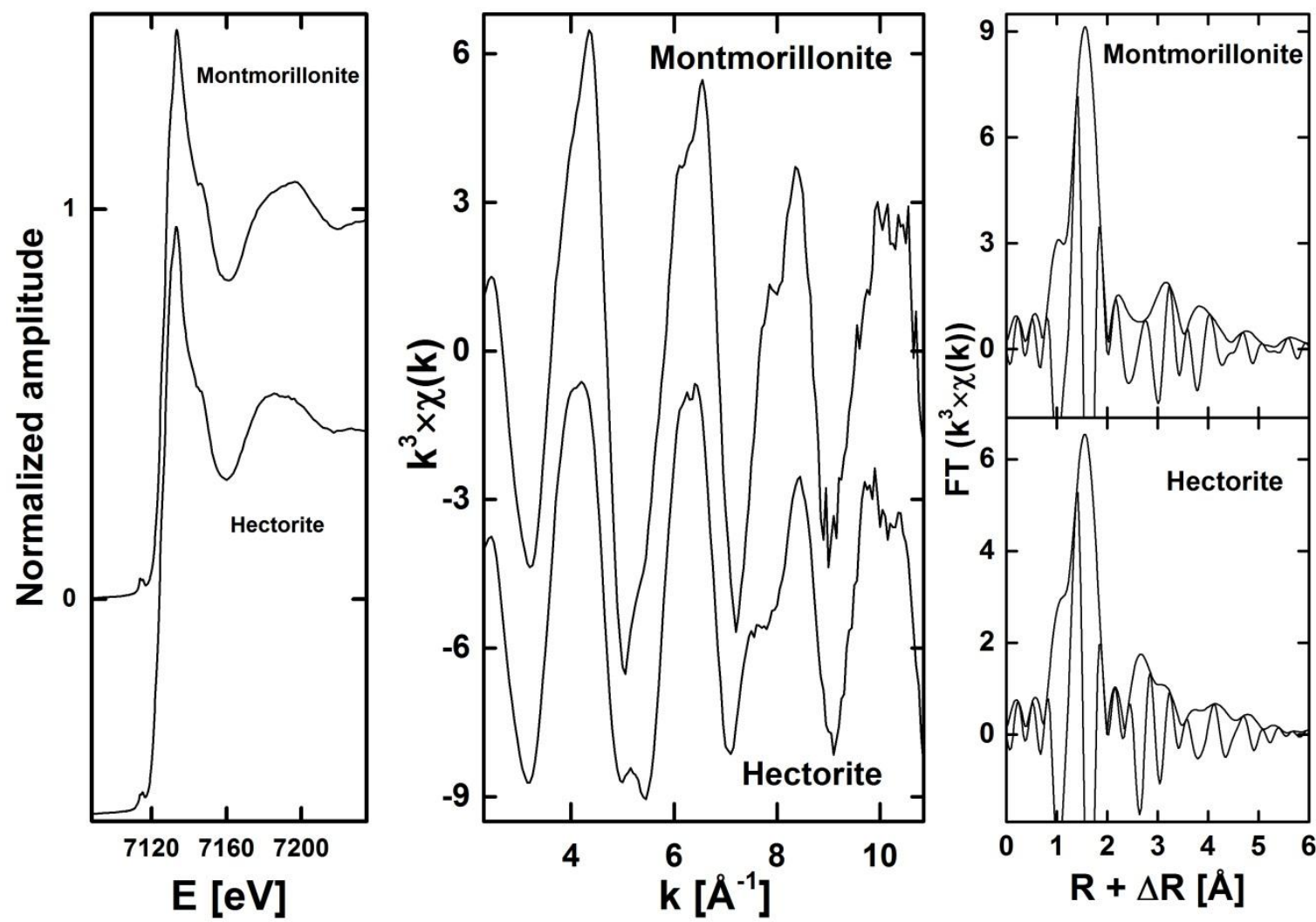

Figure 3. Comparison of experimental Fe $K$-edge XANES (left), and EXAFS spectra (middle) recorded at $\alpha=$ $35^{\circ}$ for montmorillonite and hectorite with the corresponding Fourier transforms (right). 


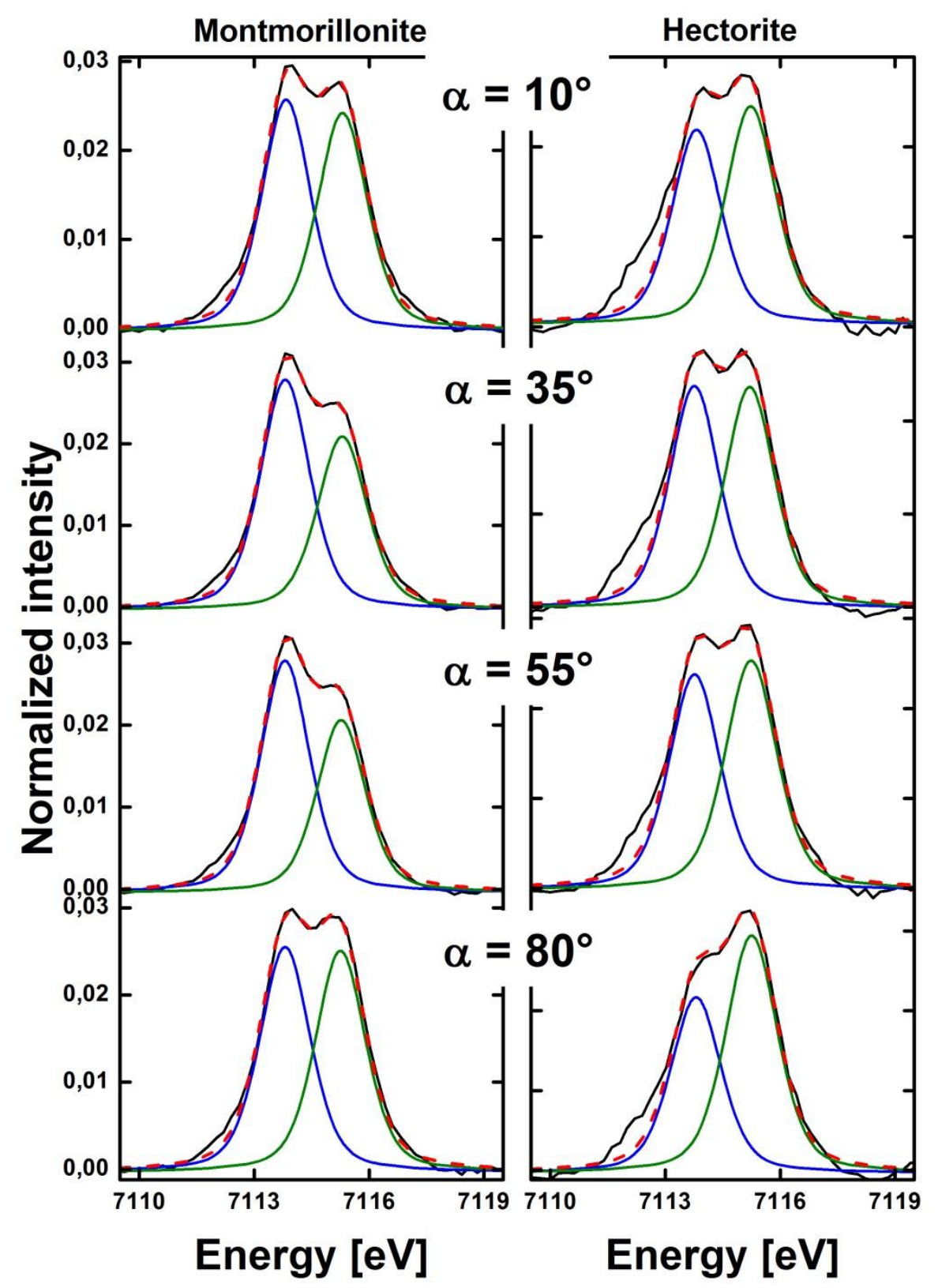

Figure 4. Normalized pre-edge spectra (solid black line) and best fits (dashed red lines) with individual components (blue and green thin lines) for montmorillonite (left) and hectorite (right). 

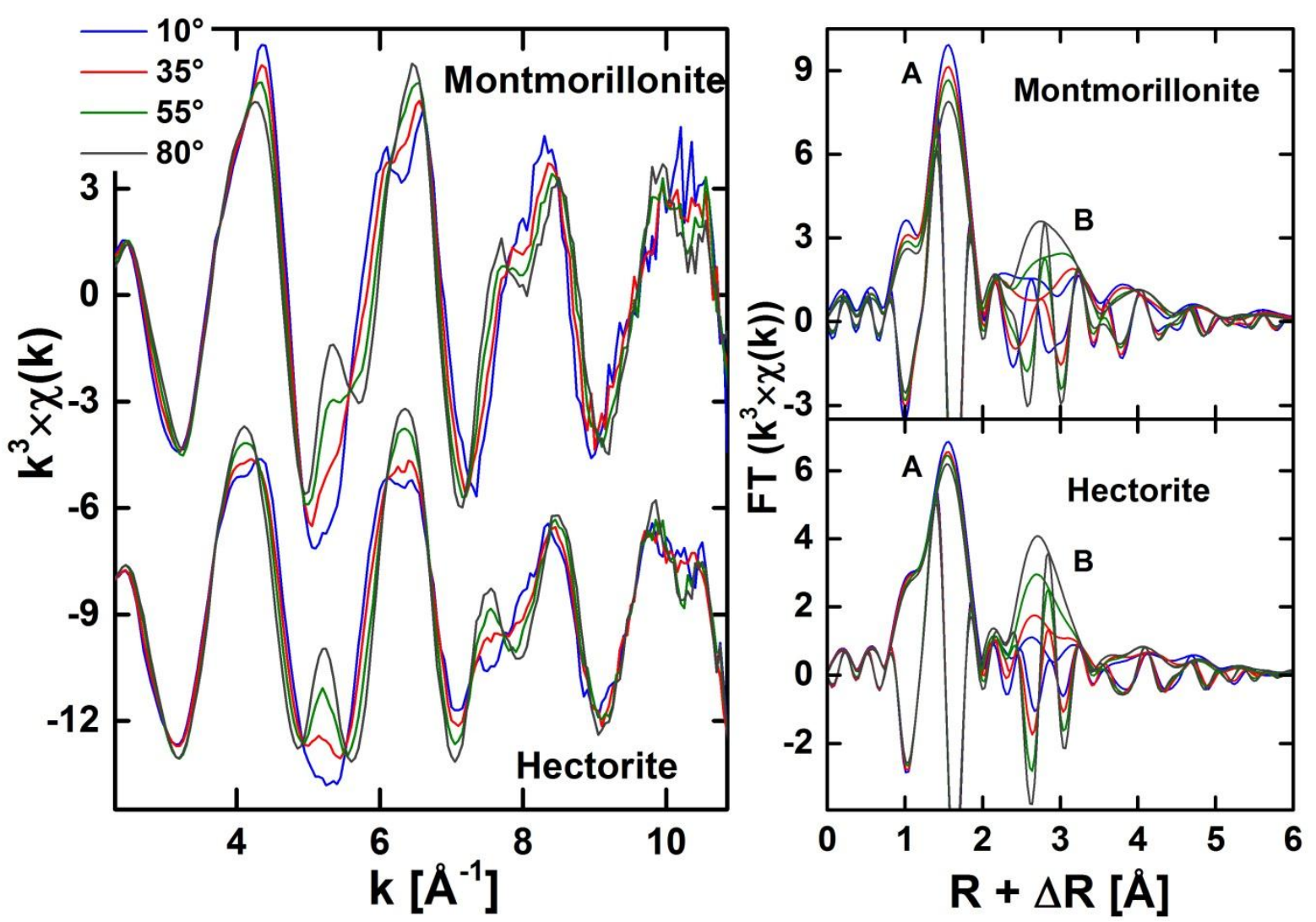

Figure 5. Experimental P-EXAFS spectra (left) with the corresponding Fourier transforms (right) for montmorillonite and hectorite. 


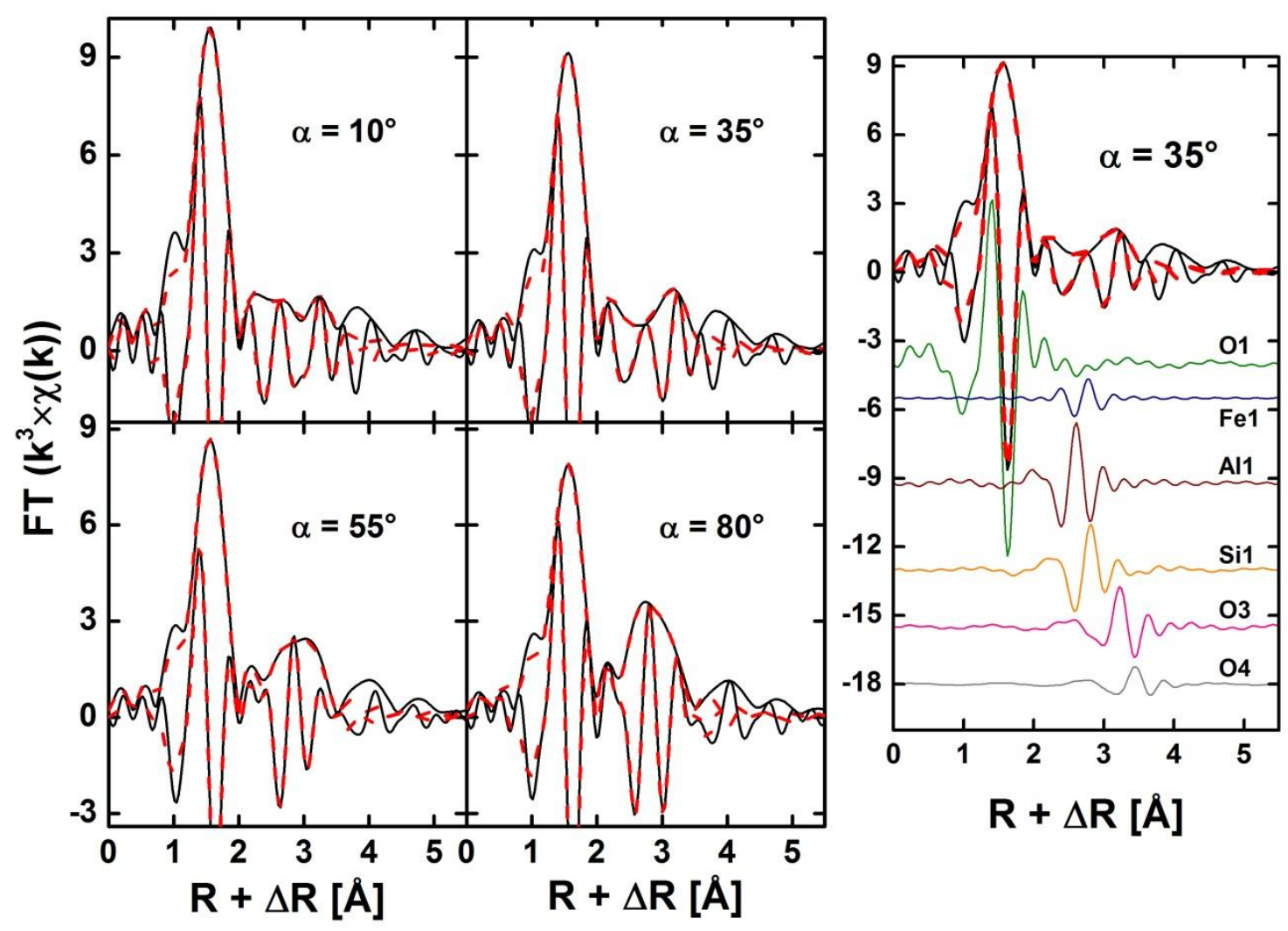

Figure 6. Experimental (solid black lines) and modeled (dashed red lines) polarized Fourier transforms for the montmorillonite data. The right panel indicates the contributions at $\alpha=35^{\circ}$ of the single atomic shells. 


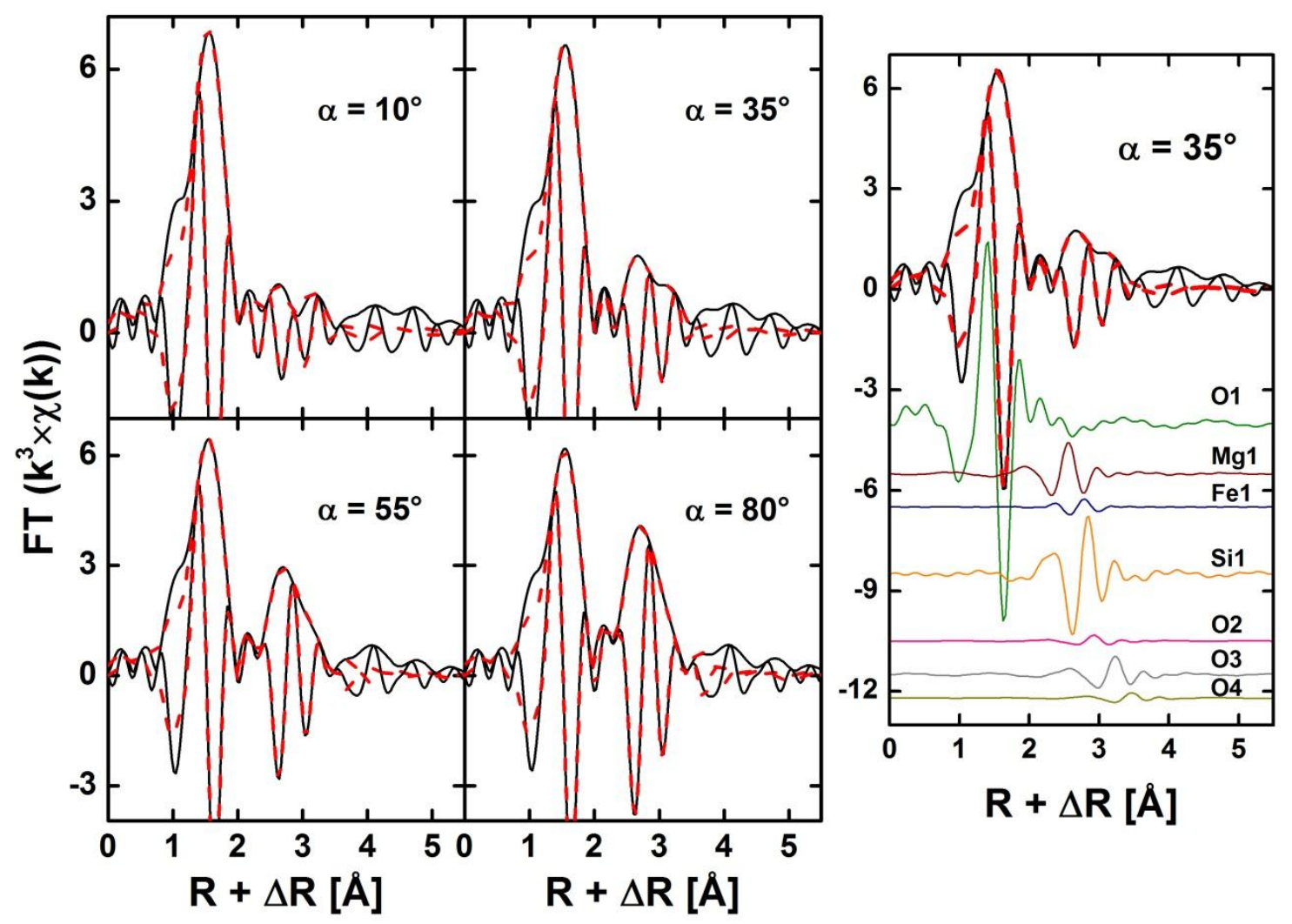

Figure 7. Experimental (solid black lines) and modeled (dashed red lines) polarized Fourier transforms for the hectorite data. The right panel indicates the contributions at $\alpha=35^{\circ}$ of the single atomic shells. 
Table 1. Main cations content of montmorillonite (SWy-1) and hectorite (SHCa-1) determined by chemical analysis (Other includes oxygen).

\begin{tabular}{cccccccc}
\hline (wt \%) & $\mathbf{L i}$ & $\mathbf{M g}$ & $\mathbf{A l}$ & $\mathbf{S i}$ & $\mathbf{F e}$ & Other & Total \\
\hline \multirow{2}{*}{ SWy-1 } & $<0.01$ & 1.36 & 8.93 & 25.84 & 2.30 & \multirow{2}{*}{61.57} & 100.00 \\
& & $( \pm 0.01)$ & $( \pm 0.07)$ & $( \pm 3.30)$ & $( \pm 0.14)$ & & \\
SHCa-1 & 0.39 & 12.15 & 0.40 & 21.08 & 0.24 & 65.74 & 100.00 \\
& $(0.01)$ & $( \pm 0.09)$ & $( \pm 0.01)$ & $( \pm 2.69)$ & $( \pm 0.01)$ & & \\
\hline
\end{tabular}


Table 2. Results from the pre-edge fitting (uncertainties on the energies are estimated to $0.1 \mathrm{eV}$ and $10 \%$ on the intensities).

\begin{tabular}{|c|c|c|c|c|c|}
\hline Sample & $\alpha$ & $\begin{array}{c}\text { Pre-edge peak } \\
\text { energy }[\mathrm{eV}]\end{array}$ & $\begin{array}{c}\text { Pre-edge peak } \\
\text { intensity }^{1}\end{array}$ & $\begin{array}{c}\text { Peak energy } \\
\text { difference }^{2}\end{array}$ & $\begin{array}{c}\text { Peak intensity } \\
\text { ratio }^{3}\end{array}$ \\
\hline \multirow{8}{*}{ Montmorillonite } & \multirow{2}{*}{$10^{\circ}$} & 7113.83 & 0.050 & \multirow{2}{*}{1.48} & \multirow{2}{*}{1.04} \\
\hline & & 7115.31 & 0.048 & & \\
\hline & \multirow{2}{*}{$35^{\circ}$} & 7113.81 & 0.055 & \multirow{2}{*}{1.49} & \multirow{2}{*}{1.31} \\
\hline & & 7115.30 & 0.042 & & \\
\hline & \multirow{2}{*}{$55^{\circ}$} & 7113.81 & 0.055 & \multirow{2}{*}{1.46} & \multirow{2}{*}{1.38} \\
\hline & & 7115.27 & 0.040 & & \\
\hline & \multirow{2}{*}{$80^{\circ}$} & 7113.81 & 0.051 & \multirow{2}{*}{1.44} & \multirow{2}{*}{1.02} \\
\hline & & 7115.25 & 0.050 & & \\
\hline \multirow{8}{*}{ Hectorite } & \multirow{2}{*}{$10^{\circ}$} & 7113.82 & 0.042 & \multirow{2}{*}{1.41} & \multirow{2}{*}{0.88} \\
\hline & & 7115.23 & 0.048 & & \\
\hline & \multirow{2}{*}{$35^{\circ}$} & 7113.76 & 0.047 & \multirow{2}{*}{1.45} & \multirow{2}{*}{1.00} \\
\hline & & 7115.21 & 0.047 & & \\
\hline & \multirow{2}{*}{$55^{\circ}$} & 7113.77 & 0.048 & \multirow{2}{*}{1.47} & \multirow{2}{*}{0.92} \\
\hline & & 7115.24 & 0.052 & & \\
\hline & \multirow{2}{*}{$80^{\circ}$} & 7113.81 & 0.044 & \multirow{2}{*}{1.45} & \multirow{2}{*}{0.72} \\
\hline & & 7115.26 & 0.061 & & \\
\hline
\end{tabular}

${ }^{1}$ peak intensities correspond to integrated areas. ${ }^{2}$ peak energy differences correspond to energy differences between the lowest energy and the highest energy pre-edge features. ${ }^{3}$ ratio of the lowest energy peak intensity to the highest energy peak intensity. 
Table 3. Quantitative EXAFS analysis for montmorillonite

\begin{tabular}{|c|c|c|c|c|c|c|c|c|c|}
\hline \multirow{2}{*}{$\alpha$} & \multicolumn{3}{|c|}{$\mathrm{Fe} \leftrightarrow \mathrm{O1}$} & \multicolumn{3}{|c|}{$\mathrm{Fe} \leftrightarrow \mathrm{Fe} 1$} & \multicolumn{3}{|c|}{ Fe $\leftrightarrow$ Al1 } \\
\hline & $N$ & $R[\AA]$ & $\sigma^{2}\left[\AA^{2}\right]$ & $N$ & $\boldsymbol{R}[\AA]$ & $\sigma^{2}\left[\AA^{2}\right]$ & $N$ & $R[\AA]$ & $\sigma^{2}\left[\AA^{2}\right]$ \\
\hline $10^{\circ}$ & $6.3(5)$ & \multirow{4}{*}{$2.01(1)$} & \multirow{4}{*}{0.005} & $0.5(1)$ & \multirow{4}{*}{$3.02(1)$} & \multirow{4}{*}{0.004} & $3.4(3)$ & \multirow{4}{*}{$3.04(1)$} & \multirow{4}{*}{0.004} \\
\hline $35^{\circ}$ & $5.8(5)$ & & & $0.4(1)$ & & & $2.6(3)$ & & \\
\hline $55^{\circ}$ & $5.5(5)$ & & & $0.2(1)$ & & & $1.4(5)$ & & \\
\hline $80^{\circ}$ & $4.9(4)$ & & & $0.1(1)$ & & & $0.6(1)$ & & \\
\hline
\end{tabular}

\begin{tabular}{|c|c|c|c|c|c|c|c|c|c|c|c|}
\hline \multirow{2}{*}{$\alpha$} & \multicolumn{3}{|c|}{$\mathrm{Fe} \leftrightarrow \mathrm{Si}$} & \multicolumn{3}{|c|}{$\mathrm{Fe} \leftrightarrow \mathrm{O3}$} & \multicolumn{3}{|c|}{$\mathrm{Fe} \leftrightarrow \mathrm{O4}$} & \multirow{2}{*}{$\begin{array}{l}\Delta E_{0}^{\mathbf{b}} \\
{[\mathrm{eV}]}\end{array}$} & \multirow{2}{*}{$\begin{array}{c}\boldsymbol{R}_{f}^{\mathrm{c}} \\
\left(\times 10^{3}\right)\end{array}$} \\
\hline & $N$ & $R[\AA]$ & $\sigma^{2}\left[\AA^{2}\right]$ & $N$ & $R[\AA]$ & $\sigma^{2}\left[\AA^{2}\right]$ & $N$ & $R[\AA]$ & $\sigma^{2}\left[\AA^{2}\right]$ & & \\
\hline $10^{\circ}$ & $1.4(7)$ & \multirow{4}{*}{$3.22(1)$} & \multirow{4}{*}{0.007} & $5.4(1.6)$ & \multirow{4}{*}{$3.79(1)$} & \multirow{4}{*}{0.004} & $2.4(2.4)$ & \multirow{4}{*}{$4.01(2)$} & \multirow{4}{*}{0.007} & \multirow{4}{*}{$6.8(4)$} & 5.6 \\
\hline $35^{\circ}$ & $3.4(3)$ & & & $5.8(1.3)$ & & & $4.2(1.9)$ & & & & 5.4 \\
\hline $55^{\circ}$ & $5.2(5)$ & & & $6.0(1.1)$ & & & $6.3(1.6)$ & & & & 5.6 \\
\hline $80^{\circ}$ & $6.6(7)$ & & & $6.1(9)$ & & & $8.0(1.3)$ & & & & 8.3 \\
\hline
\end{tabular}

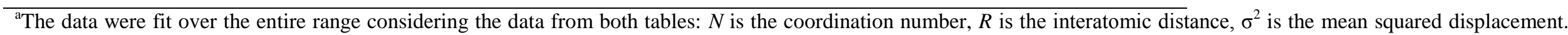

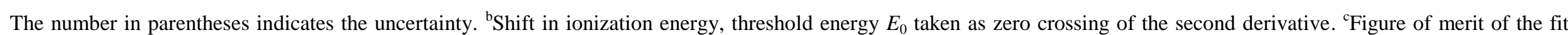
(Ravel, 2000). 
Table 4. Quantitative EXAFS analysis for hectorite ${ }^{a}$

\begin{tabular}{|c|c|c|c|c|c|c|c|c|c|c|c|c|}
\hline \multirow{2}{*}{$\alpha$} & \multicolumn{3}{|c|}{$\mathrm{Fe} \leftrightarrow \mathrm{O} 1$} & \multicolumn{3}{|c|}{$\mathrm{Fe} \leftrightarrow \mathrm{Mg1}$} & \multicolumn{3}{|c|}{$\mathrm{Fe} \leftrightarrow \mathrm{Fe} 1$} & \multicolumn{3}{|c|}{$\mathrm{Fe} \leftrightarrow \mathrm{Si} 1$} \\
\hline & $N$ & $R[\AA]$ & $\sigma^{2}\left[\AA^{2}\right]$ & $N$ & $\boldsymbol{R}[\AA]$ & $\sigma^{2}\left[\AA^{2}\right]$ & $N$ & $\boldsymbol{R}[\AA]$ & $\sigma^{2}\left[\AA^{2}\right]$ & $N$ & $\boldsymbol{R}[\AA]$ & $\sigma^{2}\left[\AA^{2}\right]$ \\
\hline $10^{\circ}$ & $5.4(5)$ & \multirow{4}{*}{$2.00(1)$} & \multirow{4}{*}{0.006} & $2.8(2)$ & \multirow{4}{*}{$3.03(1)$} & \multirow{4}{*}{0.008} & $0.3(1)$ & \multirow{4}{*}{$3.03(3)$} & \multirow{4}{*}{0.008} & $2.1(2)$ & \multirow{4}{*}{$3.24(1)$} & \multirow{4}{*}{0.007} \\
\hline $35^{\circ}$ & $5.1(5)$ & & & $1.7(6)$ & & & $0.2(1)$ & & & $3.4(6)$ & & \\
\hline $55^{\circ}$ & $4.9(4)$ & & & $1.1(6)$ & & & $0.1(1)$ & & & $5.1(6)$ & & \\
\hline $80^{\circ}$ & $4.6(4)$ & & & $0.6(1)$ & & & $0.1(1)$ & & & $6.9(7)$ & & \\
\hline
\end{tabular}

\begin{tabular}{|c|c|c|c|c|c|c|c|c|c|c|c|}
\hline \multirow{2}{*}{$\alpha$} & \multicolumn{3}{|c|}{$\mathrm{Fe} \leftrightarrow \mathrm{O} 2$} & \multicolumn{3}{|c|}{$\mathrm{Fe} \leftrightarrow \mathrm{O3}$} & \multicolumn{3}{|c|}{$\mathrm{Fe} \leftrightarrow \mathrm{O4}$} & \multirow{2}{*}{$\begin{array}{l}\Delta E_{0}^{\mathbf{b}} \\
{[\mathrm{eV}]}\end{array}$} & \multirow{2}{*}{$\begin{array}{c}\boldsymbol{R}_{f}^{\mathrm{c}} \\
\left(\times 10^{3}\right)\end{array}$} \\
\hline & $N$ & $R[\AA]$ & $\sigma^{2}\left[\AA^{2}\right]$ & $N$ & $R[\AA]$ & $\sigma^{2}\left[\AA^{2}\right]$ & $N$ & $R[\AA]$ & $\sigma^{2}\left[\AA^{2}\right]$ & & \\
\hline $10^{\circ}$ & $0.1(1)$ & \multirow{4}{*}{$3.48(1)$} & \multirow{4}{*}{0.006} & $2.4(1.3)$ & \multirow{4}{*}{$3.78(1)$} & \multirow{4}{*}{0.008} & $0.1(1)$ & \multirow{4}{*}{ 4.01(1) } & \multirow{4}{*}{0.008} & \multirow{4}{*}{$6.6(2)$} & 4.7 \\
\hline $35^{\circ}$ & $0.6(1.1)$ & & & $2.8(1.5)$ & & & $1.0(1.3)$ & & & & 3.6 \\
\hline $55^{\circ}$ & $1.4(1.1)$ & & & $3.9(1.6)$ & & & $3.7(1.4)$ & & & & 2.9 \\
\hline $80^{\circ}$ & $1.4(6)$ & & & 4.1(1.9) & & & $5.5(5)$ & & & & 4.4 \\
\hline
\end{tabular}

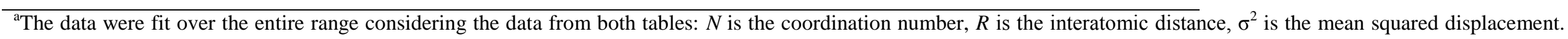

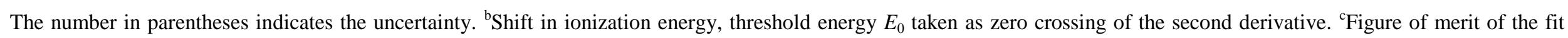
(Ravel, 2000). 
Ankudinov A. L., Ravel B., Rehr J. J., and Conradson S. D. (1998) Real-space multiple-scattering calculation and interpretation of $\mathrm{x}$-ray-absorption near-edge structure. Physical Review $B$ 58, 7565-7576.

Bishop M. E., Dong H., Kukkadapu R. K., Liu C., and Edelmann R. E. (2011) Bioreduction of Fe-bearing clay minerals and their reactivity toward pertechnetate (Tc-99). Geochimica et Cosmochimica Acta 75, 5229-5246.

Bishop M. E., Glasser P., Dong H., Arey B., and Kovarik L. (2014) Reduction and immobilization of hexavalent chromium by microbially reduced Fe-bearing clay minerals. Geochimica et Cosmochimica Acta 133, 186-203.

Breu J., Seidl W., and Stoll A. (2003) Fehlordnung bei Smectiten in Abhängigkeit vom Zwischenschichtkation. Zeitschrift für anorganische und allgemeine Chemie 629, 503-515.

Drits V. A. and Manceau A. (2000) A model for the mechanism of Fe3+ to Fe2+ reduction in dioctahedral smectites. Clays and Clay Minerals 48, 185-195.

Ernstsen V., Gates W. P., and Stucki J. W. (1998) Microbial Reduction of Structural Iron in Clays-A Renewable Source of Reduction Capacity. J. Environ. Qual. 27, 761-766.

Gates W. P. (2008) Cation mass-valence sum (CM-VS) approach to assigning OH-bending bands in dioctahedral smectites. Clays and Clay Minerals 56, 10-22.

Gates W. P., Stucki J. W., and Kirkpatrick R. O. (1996) Structural properties of reduced Upton Montmorillonite. Physics and Chemistry of Minerals 23, 535-541.

Gates W. P., Bouazza A., and Churchman G. J. (2009) Bentonite clay keeps pollutants at bay. Elements 5, 105-110.

Gates W. P., Slade P. G., Manceau A., and Lanson B. (2002) Site occupancies by iron in nontronites. Clays and Clay Minerals 50, 223-239.

Gates W. P., Jaunet A.-M., Tessier D., Cole M. A., Wilkinson H. T., and Stucki J. W. (1998) Swelling and texture of iron-bearing smectites reduced by bacteria. Clays and Clay Minerals 46, 487-497.

Golubev S. V., Bauer A., and Pokrovsky O. S. (2006) Effect of pH and organic ligands on the kinetics of smectite dissolution at 25\&\#xa0; ${ }^{\circ} \mathrm{C}$. Geochimica et Cosmochimica Acta 70, 4436-4451.

Gorski C. A., Klüpfel L. E., Voegelin A., Sander M., and Hofstetter T. B. (2013) Redox Properties of Structural Fe in Clay Minerals: 3. Relationships between Smectite Redox and Structural Properties. Environmental Science \& Technology 47, 13477-13485.

Güven N. (1988) Smectites. In Hydrous Phyllosilicates, Reviews in Mineralogy, Vol. 19 (ed. S. W. Bailey), pp. 497-559. Mineralogical Society of America, Washington, DC.

Güven N. (2009) Bentonites - clay for molecular engineering. Elements 5, 89-92.

Hahn J. E., Scott R. A., Hodgson K. O., Doniach S., Desjardins S. R., and Solomon E. I. (1982) Observation of an electric quadrupole transition in the X-ray absorption spectrum of a $\mathrm{Cu}(\mathrm{II})$ complex. Chem. Phys. Lett. 88, 595-598.

Komadel P., Madejová J., and Stucki J. W. (2006) Structural Fe(III) reduction in smectites. Applied Clay Science 34, 88-94.

Labouriau A., Kim Y. W., Chipera S., Bish D. L., and Earl W. L. (1995) A F-19 nuclear magnetic resonance study of natural clays. Clays and Clay Minerals 43, 697-704.

Madejova J. and Komadel P. (2001) Baseline studies of The Clay Minerals Society Source Clays: Infrared methods. Clays and Clay Minerals 49, 410-432.

Manceau A. (1990a) DISTRIBUTION OF CATIONS AMONG THE OCTAHEDRA OF PHYLLOSILICATES INSIGHT FROM EXAFS. Canadian Mineralogist 28, 321-328.

Manceau A. (1990b) Distribution of cations among the octahedra of phyllosilicates: insight from EXAFS. Canadian Mineralogist 28, 321-328. 
Manceau A. and Gates W. P. (1997) Surface structural model for ferrihydrite. Clays and Clay Minerals 43, 448-460.

Manceau A., Chateigner D., and Gates W. P. (1998) Polarized EXAFS, distance-valence least-squares modeling (DVLS) and quantitative texture analysis approaches to the structural refinement of Garfield nontronite. Physics and Chemistry of Minerals 25, 347-365.

Manceau A., Bonnin D., Stone W. E. E., and Sanz J. (1990) Distribution of Fe in the octahedral sheet of trioctahedral micas by polarized EXAFS. Physics and Chemistry of Minerals 17, 363-370.

Manceau A., Lanson B., Drits V. A., Chateigner D., Gates W. P., Wu J., Huo D., and Stucki J. W. (2000a) Oxidation-reduction mechanism of iron in dioctahedral smectites: I. Crystal chemistry of oxidized reference nontronites. American Mineralogist 85, 133-152.

Manceau A., Drits V. A., Lanson B., Chateigner D., Wu J., Huo D., Gates W. P., and Stucki J. W. (2000b) Oxidation-reduction mechanism of iron in dioctahedral smectites: II. Crystal chemistry of reduced Garfield nontronite. American Mineralogist 85, 153-172.

Mering J. and Glaeser R. (1954) Sur le rôle de la valence des cations échangeables dans la montmorillonite. Bulletin de la Société française de Minéralogie et Cristallographie 77, 519530.

Meunier A. (2005) Clays. Springer, Berlin Heidelberg.

Neumann A., Petit S., and Hofstetter T. B. (2011) Evaluation of redox-active iron sites in smectites using middle and near infrared spectroscopy. Geochimica et Cosmochimica Acta 75, 2336 2355.

Pentráková L., Su K., Pentrák M., and Stucki J. W. (2013) A review of microbial redox interactions with structural Fe in clay minerals. Clay Minerals 48, 543-560.

Proux O., Biquard X., Lahera E., Menthonnex J.-J., Prat A., Ulrich O., Soldo Y., Trévisson P., Kapoujvan G., Perroux G., Taumer P., Grand O., Jeantet P., Deleglise M., Roux J.-P., and Hazemann J.-L. (2005) FAME: a new beamline for X-ray absorption investigation of very-diluted systems of environmental materials and biological interest. Physica Scripta T115, 970-973.

Ravel B. (2000) EXAFS Analysis with Feff and Feffit. Part 2: Commentary, report.

Ravel B. and Newville M. (2005) ATHENA, ARTEMIS, HEPHAESTUS: data analysis for X-ray absorption spectroscopy using IFEFFIT. Journal of Synchrotron Radiation 12, 537-541.

Schlegel M. L., Manceau A., Chateigner D., and Charlet L. (1999) Sorption of metal ions on clay minerals. I. Polarized EXAFS evidence for the adsorption of cobalt on the edges of hectorite particles. Journal of Colloid and Interface Science 215, 140-158.

Shannon R. D. (1976) Revised effective ionic radii and systematic studies of interatomic distances in halides and chalcogenides. Acta Crystallographica Section A 32, 751-767.

Stucki J. W. (1988) Structural iron in smectites. In Iron in soils and clay minerals, NATO ASI series, Vol. 217 (ed. J. W. G. Stucki, B.A. and U. Schwertmann), pp. 625-675. Springer.

Stucki J. W. (2006) Chapter 8 Properties and Behaviour of Iron in Clay Minerals. In Developments in Clay Science, Vol. Volume 1 (ed. B. K. G. T. Faïza Bergaya and L. Gerhard), pp. 423-475. Elsevier.

Swarnakar R., Brandt K. B., and Kydd R. A. (1996) Catalytic activity of Ti- and Al-pillared montmorillonite and beidellite for cumene cracking and hydrocracking [A3411]. Applied catalysis. A, General 142, 161.

Thien B., Godon N., Hubert F., Angeli F., Gin S., and Ayral A. (2010) Structural identification of a trioctahedral smectite formed by the aqueous alteration of a nuclear glass. Applied Clay Science 49, 135-141.

Thomas J., Glass H. D., White W. A., and Trandel R. M. (1977) FLUORIDE CONTENT OF CLAYMINERALS AND ARGILLACEOUS EARTH MATERIALS. Clays and Clay Minerals 25, 278-284.

Tsipursky S. I. and Drits V. A. (1984) The distribution of octahedral cations in the 2-1 layers of dioctahedral smectites studied by oblique-texture electron-diffraction. Clay Minerals 19, 177193. 
Vantelon D., Montarges-Pelletier E., Michot L. J., Pelletier M., Thomas F., and Briois V. (2003) Iron distribution in the octahedral sheet of dioctahedral smectites. An Fe K-edge X-ray absorption spectroscopy study. Physics and Chemistry of Minerals 30, 44-53.

Westre T. E., KennepohI P., DeWitt J. G., Hedman B., Hodgson K. O., and Solomon E. I. (1997) A multiplet analysis of Fe K-edge 1s->3d pre-edge features of iron complexes. Journal of the American Chemical Society 119, 6297-6314.

Wilke M., Farges F., Petit P.-E., Brown G. E., and Martin F. (2001) Oxidation state and coordination of Fe in minerals: an Fe K-XANES spectroscopic study. American Mineralogist 86, 714-730.

Williams L. B., Haydel S. E., and Ferrell R. E. (2009) Bentonite, Bandaids, and Borborygmi. Elements 5, 99-104.

Yang J., Kukkadapu R. K., Dong H., Shelobolina E. S., Zhang J., and Kim J. (2012) Effects of redox cycling of iron in nontronite on reduction of technetium. Chemical Geology 291, 206-216. 